J.I. Lubinski, K. Druet, A. Olszewski, A. Neyman, J. Sikora

Department of Machine and Automotive Design, Faculty of Mechanical Engineering, Gdansk University of Technology, Narutowicza 11/12, Gdansk, 80-233, Poland

jacek.lubinski@pg.gda.pl

\title{
A MULTI RIG SCREENING TEST FOR THIN CERAMIC COATINGS IN BIO - TRIBOLOGICAL APPLICATIONS
}

\begin{abstract}
A method is presented for the comparative testing of wear resistance of ceramic coatings made from materials potentially feasible in tribo - medical applications, mainly orthopaedic implants made from ceramics coated metals for low cost, long life and low wear particle emission into the body. The method was devised as the main tool for use in research and is comprised of flat on flat and ball on flat surface (sliding) tests. Seven ceramic coatings were chosen as potentially feasible for the application area known to perform well in low viscosity fluid lubrication condition. The materials used in coatings were diamond like carbon (DLC), diamond like carbon with tungsten additive (DLC-W), titanium nitride (TiN), titanium carbide (TiC), silicon carbide ( $\mathrm{SiC})$, chromium nitride $(\mathrm{CrN})$, carbon nitride $(\mathrm{CNx})$. The coatings tested were deposited in vacuum to a stainless steel substrate with the use of several methods, each suited to the coating material; The methods were the following: cathode arc evaporation (ARC), magnetron sputtering (MAG), plasma assisted chemical vapour deposition (PACVD), impulse reactive magnetron sputtering (IRMS) and a combined method ARC-MAG-RF-PACVD (radio frequency assisted - RF); A multiple role PT-3 tribometer was used for flat on flat surface tests (ring shaped surface) and a reciprocating linear motion TPZ-1 tribometer for ball on flat surface tests and a CSEM REVETEST ${ }^{\circledR}$ Scratch Tester to perform standard scratch test in air on coatings. A set of results was obtained illustrating the limiting load for each coating (the load inflicting rapid destruction of the coating) and the endurance under light loading conditions. As lubricating agents distilled water and saline water solution were used. Test results examples are presented and discussed as an illustration of the method's usability for the target application area.
\end{abstract}

Key words: ceramic coatings, tribological wear, tribometry, screening test

\section{BACKGROUND}

The use of ceramic coatings is on the increase thanks to some favourable characteristics of these materials:

- hardness

- resistance to wear

- resistance to aggressive chemicals

Ceramic coatings deposited on a metallic substrate are nowadays an increasingly common means of improving the performance of mechanical components. A properly applied ceramic coating can result in a component combining the favourable features of material groups: hardness and wear resistance of ceramics with the ductility and tensile strength of metals. Especially in moving parts exposed to friction. 
A variety of chemical compositions and application techniques provide for a wide choice of coating solutions for tribological applications; That also results in the need for a usable and simple method of experimental validation of the performance of coatings. In case of application of a coating to an artificial human joint implant for wear control and usable life extension there is a need for tests on real life implants used as specimens, which makes the procedure extremely costly. Prior to that stage of testing a reliable method is needed to validate the performance of various coatings available. The method must account for important factors and operating conditions influencing wear in a real life setting to aid the coating selection process.

A methodical comparison of results from tests on several tribometers (w. 'simple geometry of contact') for a chosen group of materials can prove as a helpful and economical tool to be used in the process of selecting materials for medical applications.

\section{PROBLEM FORMULATION}

\section{The usage of ceramic coatings in medical applications}

In medical applications the areas of interest to engineers and tribologists are, in general: medical tools and equipment, and prosthetic implants. In these applications coatings deposited on substrate material modify the surface properties to offer an array of advantages, ranging from corrosion resistance, through decreased wear, to bacteriostatic action. In case of improved wear performance in both, tools used in contact with the living tissue and implants, the operating conditions are extremely difficult. The loads are by definition variable and often unpredictable, the environment is highly corrosive to most metals (most common engineering materials), the lubrication, if present, is a water based low viscosity fluid. Also both concentrated and distributed contacts occur in the same application, as well as the action of third body hard particles between component bodies in contact subjected to friction.

\section{Comparative tribological testing}

It is one of the most difficult tasks in tribology to select the right method for testing. Despite the existence of numerous tribometer types and standard tests researchers often find it difficult to reproduce the tribological process with satisfactory accuracy in laboratory conditions. That results directly from the complexity of tribological processes. Examples are known of research being carried out on the problems of repeatability and reproducibility of tribological experiments [1, 2]. So far, the task of experimental prediction of the real life performance of a tribo system composed of novel materials remains still to be perfected.

\section{Modified screening test for comparing tribological properties of ceramic coatings in medical applications}

The study presented was aimed at comparing various coating compounds for improved performance of metallic components in sliding regime; Potential target applications for coatings considered were medical tools [7] and joint implants [8]. Because of choosing numerous materials and a rather broad area of possible use it was decided to use several 
tests inflicting different working conditions on the specimens. Three types of contact were accounted for when selecting test types: distributed contact (flat-on-flat), concentrated contact (ball-on-flat) and a 'hard body' concentrated contact; The latter being the simulation of the action of a hard particle of wear debris caught between sliding coated surfaces.

The approach of using more than one experimental technique in friction and wear research is well known in bio-tribology [1, 2, 5], as well as the concept of a screening test $[8,10]$. Still there seems to be insufficient consideration for the experiment planning with regard to comparative analysis on the basis of data sets obtained for different conditions. It can be difficult to compare results from tribological experiments carried out on different rigs and relate the comparison criteria to real life conditions. For the above reasons a simple method of ranking the materials in the tested set was proposed, using typical results from available tribological tests. The method relies on comparing the results in each test set and awarding points to materials accordingly to simple criteria - best material is given lowest point score. After applying the procedure to all result sets an overall score is calculated for each material, which allows for a global comparison between all the materials used in testing.

\section{EXPERIMENTAL TESTING}

Tests were carried out on specimens machined from PN standard 1H13 grade stainless steel (equivalent to EN/DIN X10Cr13, AISI/ASTM 410, BS 410S21), heat treated to 52 Rockwell C scale hardness. All tests in flat-on-flat and ball-on-flat configurations were carried out with either distilled water or medical saline lubrication; In scratch tests a Rockwell type diamond stylus was used as a counter specimen against a clean and dry ceramics coated surface.

\section{Distributed contact unidirectional sliding - ring shaped flat-on-flat}

Flat-on-flat tests were carried out on a PT-3 multi purpose tribometer [11] presented in Figure 1 along with a schematic view of specimens used. In the test faces of two cylindrical specimens were sliding in a rotational motion with top specimen rotating and the bottom specimen being held motionless and pressed against the top one by the action of the loading device. Detailed test conditions and principle results are listed in Table 1. Tests are run at constant velocity and load with continuous digital recording of velocity, load and friction torque. Data post processing yields friction coefficient. The contact surfaces of the specimen pair are fully immersed in the lubricating agent throughout the test. 

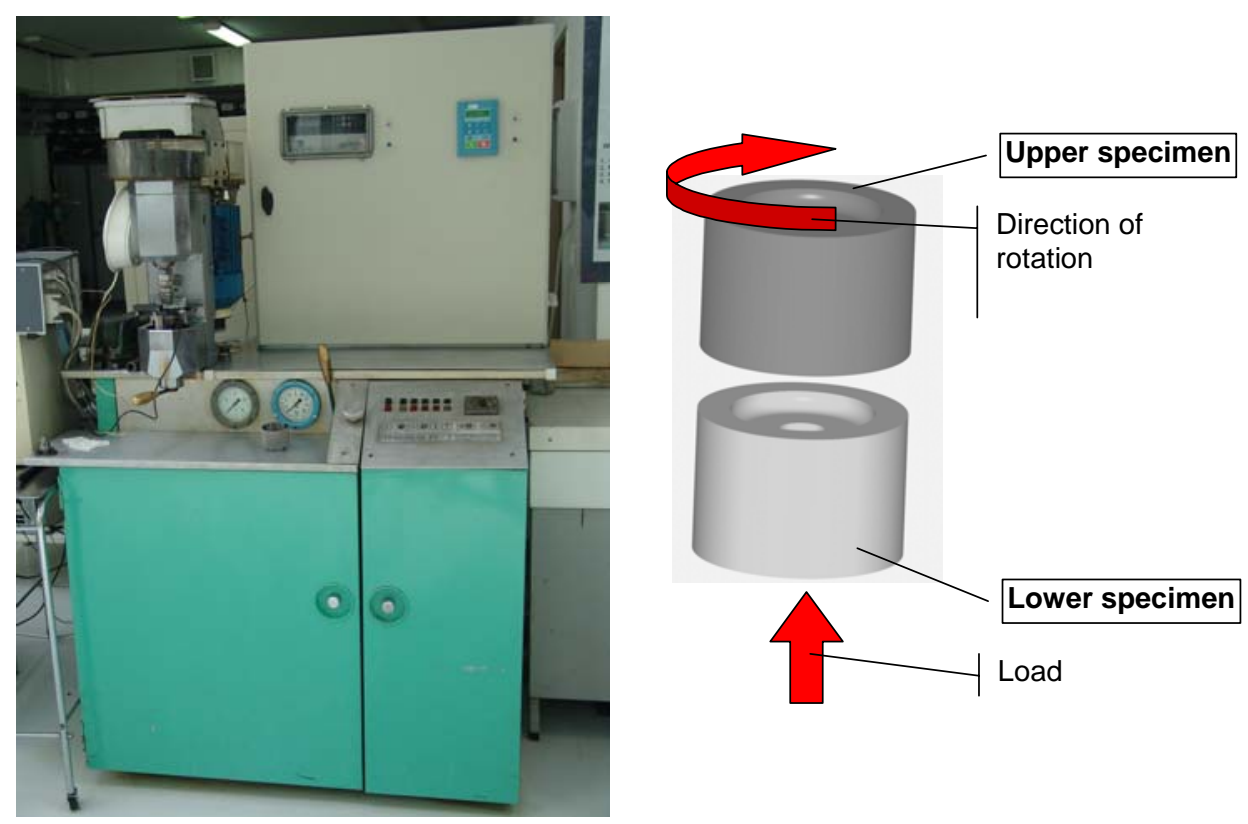

Fig.1. PT-3 tribometer for unidirectinal sliding tests in flat on flat contact (left) and contact geometry with the orientation of load and motion vectors marked (right)

Table 1 Unidirectional sliding test conditions in PT-3 Tribometer and results recorded in tests

\begin{tabular}{ll}
\hline & Test conditions: \\
\hline Contact geometry: & flat on flat, ring shape surf. \\
Mean surface pressure: & $4 \mathrm{MPa}$ (constant) \\
Sliding velocity: & $0.05 \mathrm{~m} / \mathrm{s}$ (constant) \\
Lubrication: & - distilled water \\
& - saline solution \\
Same coating on both specimens
\end{tabular}

\begin{tabular}{l}
\hline \multicolumn{1}{c}{ Results: } \\
\hline Test endurance till coating destroyed \\
Friction coefficient
\end{tabular}

For the purpose of further investigation of the wear process taking place on the specimen surface tests were conducted with intermittent examination of the lower (motionless) specimen surface and documentation with the use of digital macroscopic and microscopic photography and SEM imaging (Fig. 2).
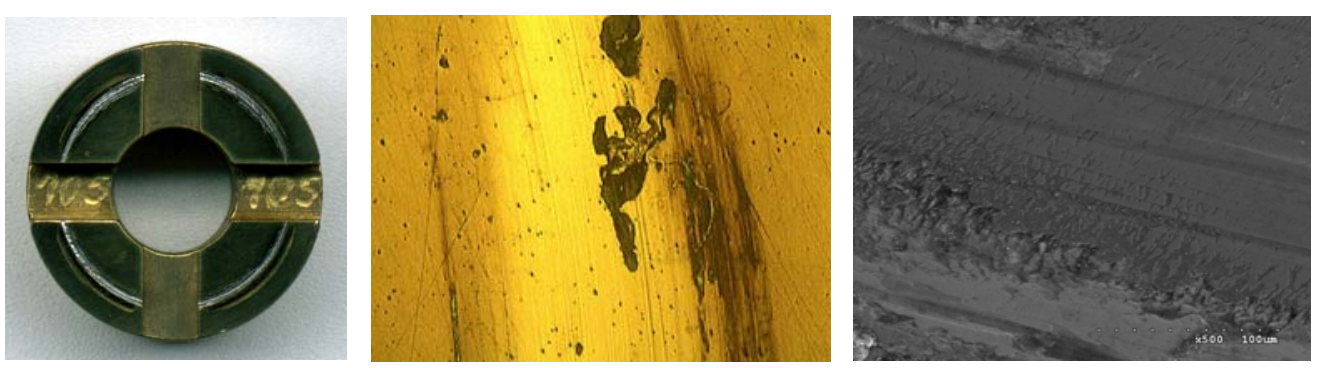

Fig. 2. Images of a TiN coated specimen after testing on PT-3 Tribometer, saline lubrication. Macroscopic image of the worn working face of the non rotating specimen (left); Optical microscopy photograph of the worn and broken coating (centre); SEM image of the border zone of the wear mark (right). 


\section{Concentrated contact reciprocating sliding - ball-on-flat}

The test rig used in ball-on-flat reciprocating sliding tests was the TPZ-1 tribometer using $5 \mathrm{~mm}$ diameter balls and prismatic, flat faced counter specimens (Fig. 3). Test conditions for all tests and results included in data set for comparison are listed in Table 2. The tests are run at constant load and a sinusoidal cycle oscillating velocity (constant rpm of the drive motor). Lubrication is provided by full immersion of the sliding pair in the lubricant.
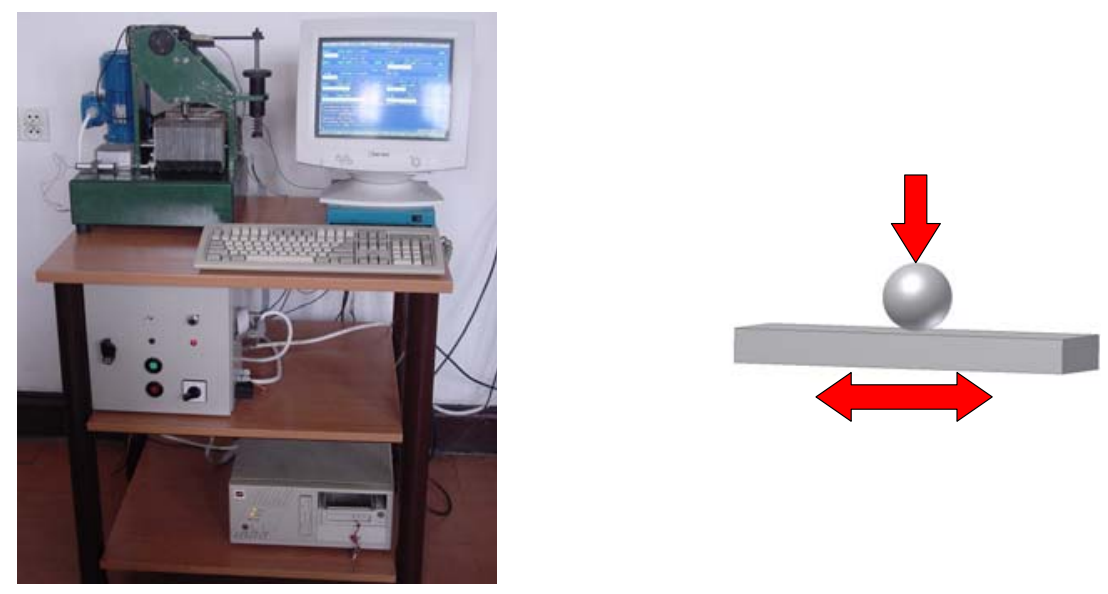

Fig. 3. TPZ-1 tribometer for reciprocating sliding tests in concentrated contact (left) and contact geometry with the orientation of load and motion vectors marked (right)

Table 2. Concentrated contact reciprocating sliding test conditions in TPZ-1 Tribometer and results recorded in tests

\begin{tabular}{lc}
\hline & Test conditions: \\
\hline Contact geometry: & ball $(5 \mathrm{~mm})$ on flat \\
Hertzian contact stress: & $1.15 \mathrm{GPa}$ \\
Sliding velocity (max.): & $0.1 \mathrm{~m} / \mathrm{s}$ \\
Stroke: & $40 \mathrm{~mm}$ \\
Lubrication: & - distilled water \\
& - saline solution \\
Same coating on both specimens & \\
\hline \multicolumn{2}{c}{ Results: } \\
\hline Wear mark surface area \\
Test endurance till coating destroyed
\end{tabular}

The tribometer is designed to perform wear tests by running a long test with intermittent stops and wear measurement on specimens. This allows to record the kinetics of wear and accurately observe the moment of coating perforation or break off or destruction by 
other mechanism. An example of wear development on the surface of the ball is presented in Figure 4. Wear can be observed as an increasing flat patch on the ball surface. With the use of calibrated optical microscope coupled to a digital camera the size (diameter) of the wear patch can be measured and surface area of the wear mark can be calculated.
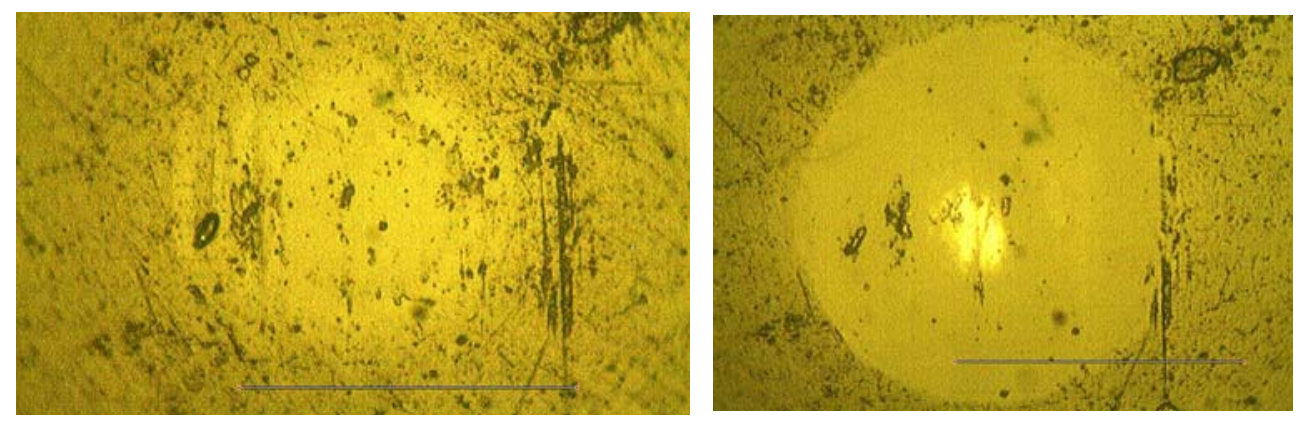

Fig. 4. An optical microscopy photograph of the DLC coated stainless steel ball surface before (left) and after $36000 \mathrm{~s}$ of testing in TPZ-1 tribometer (right) with saline lubrication.

\section{'Hard body' concentrated contact - conical indenter on flat scratch testing}

Each coating was tested for cohesive and adhesive damage resistance with the use of the CSEM REVETEST ${ }^{\circledR}$ Scratch Tester (Fig. 4, 5). In the test a diamond indenter is sliding at a constant velocity across the surface of the specimen, while the force acting on the indenter and pushing into the tested coating is linearily increased. Test conditions and results recorded are listed in Table 4.3.

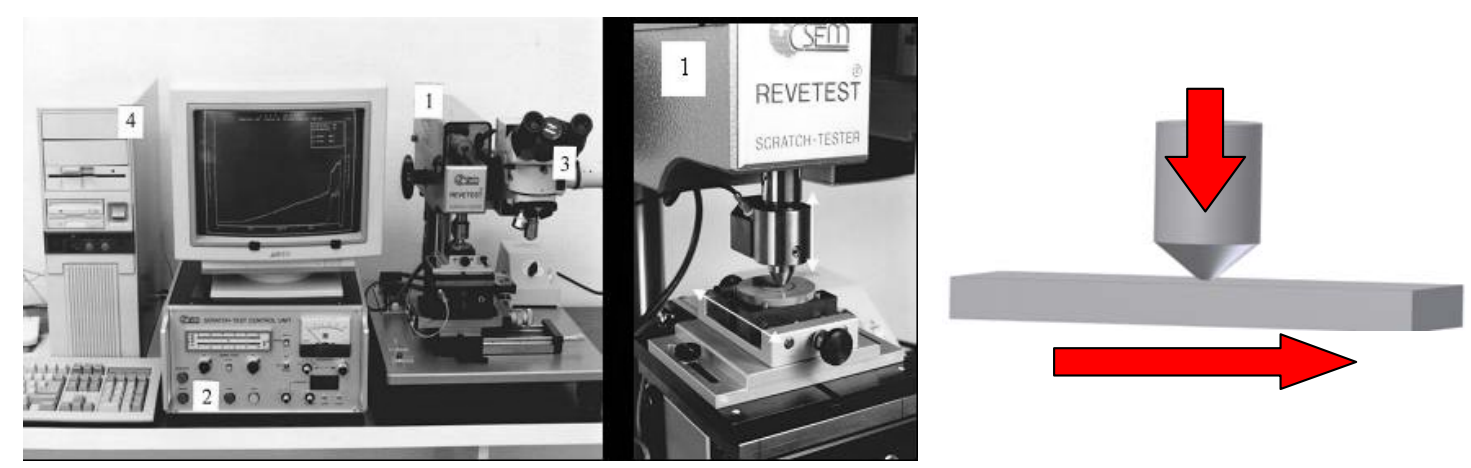

Fig. 5. CSEM REVETEST ${ }^{\circledR}$ Scratch Tester (left) and scratch test contact geometry with the orientation of load and motion vectors marked (right) 
Table 3. Scratch test conditions in CSEM REVETEST® Scratch Tester and results recorded in tests

\begin{tabular}{lc}
\hline & Test conditions: \\
\hline Contact geometry: & Rockwell C indenter on flat \\
Load range: & $0-100 \mathrm{~N}$ \\
Load increase rate: & $100 \mathrm{~N} / \mathrm{min}$ \\
Sliding velocity: & $10 \mathrm{~mm} / \mathrm{min}$ \\
Scratch length: & $10 \mathrm{~mm}$ \\
Lubrication: & none, dry test \\
\hline \multicolumn{2}{c}{ Results: } \\
\hline $\mathrm{L}_{\mathrm{c} 1}-$ cohesive damage critical load \\
$\mathrm{L}_{\mathrm{c} 2}-$ adhesive damage critical load \\
\hline
\end{tabular}

In Figure 6 a plot is presented representing friction force as a function of increasing load obtained in a test performed on TiN coating. The plot is accompanied by optical microscopy photographs of the scratch which allow to determine the critical load of cohesive and adhesive damage.

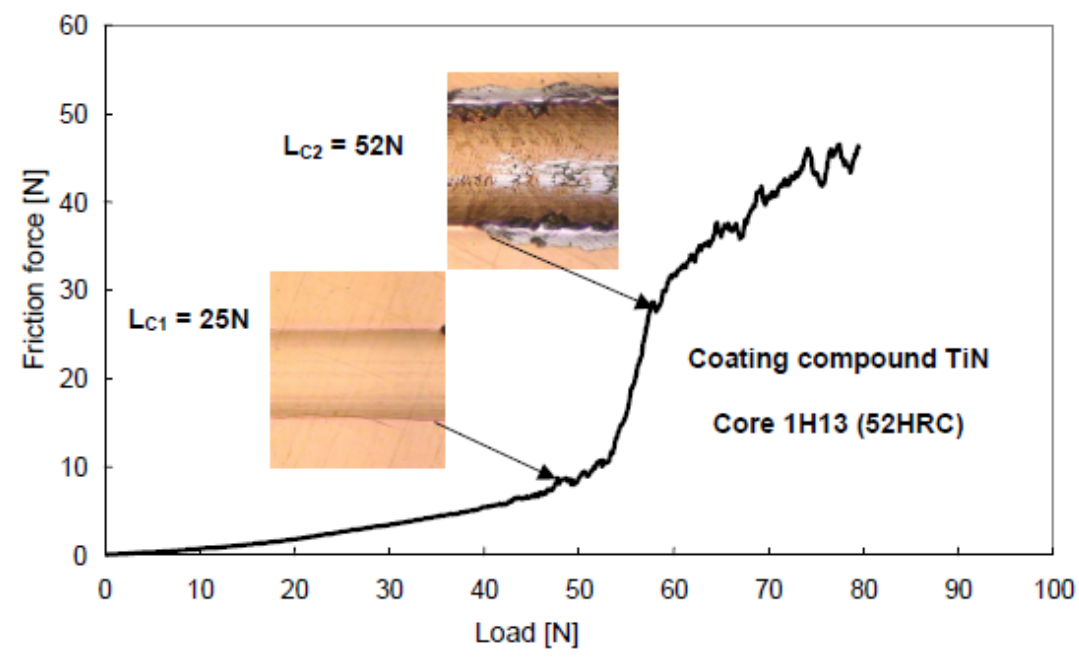

Fig. 6. Scratch Test result plot with critical loads $\left(\mathrm{L}_{c 1}, \mathrm{~L}_{\mathrm{c} 2}\right)$ and microscopic images of damaged TiN coating

\section{RESULTS AND DISCUSSION}

Each test provides different data to the global set used as a basis for the comparison of the coatings tested. In Figures 7 through 11 global results obtained in all tests performed are presented. As it can be easily observed in each type of test substantial differences between coating materials occur. Also, as could be expected, the differences between materials within a result set from one test do not correspond to those obtained in other tests. This observation confirms the concept, which lay basis for the work on the presented method for screen testing - only when several different testing configurations (test rigs) are used alongside the performance of the material can be correctly reflected in the laboratory conditions. 


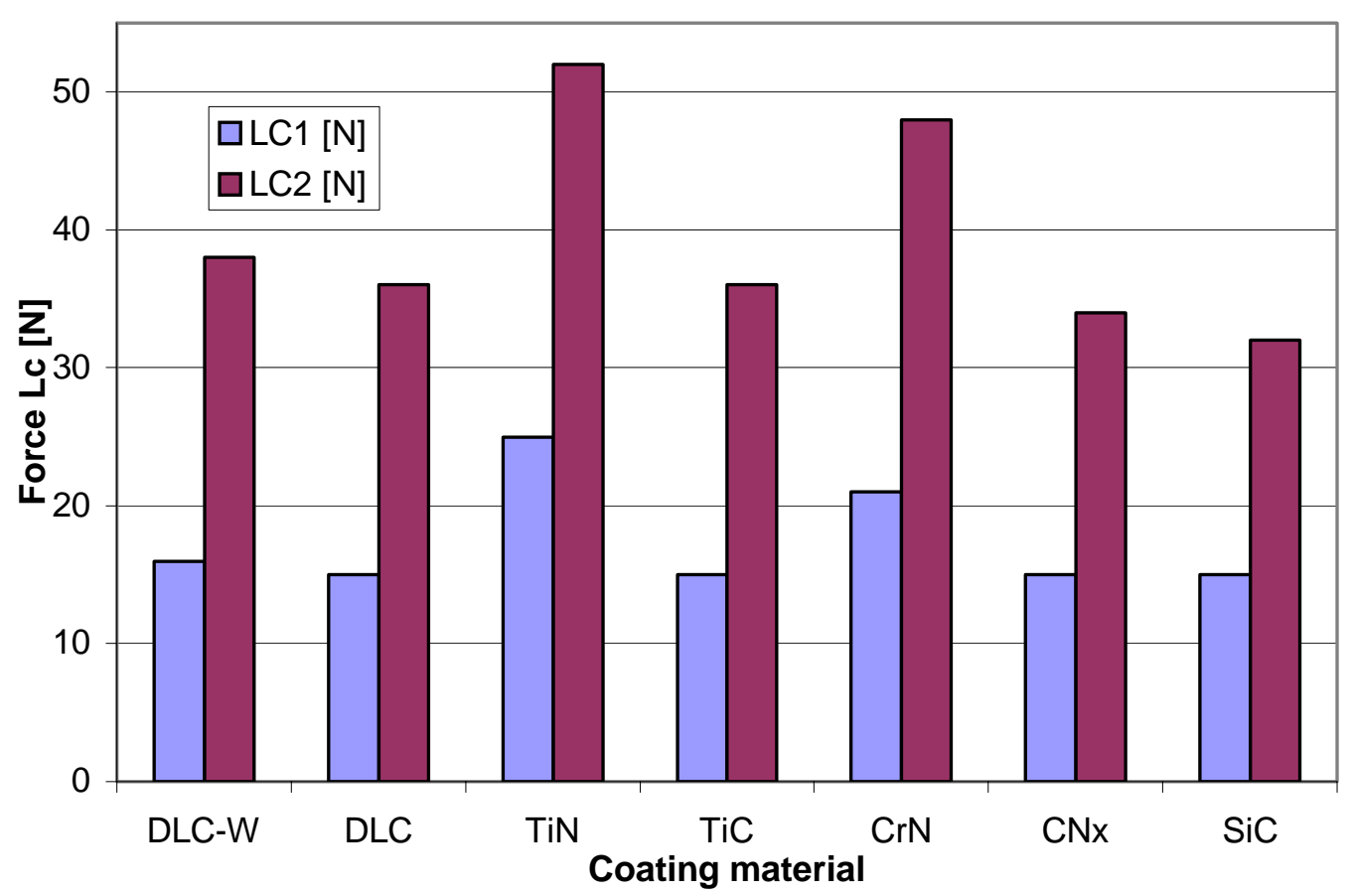

Fig. 7. Critical forces in scratch test $\left(\mathrm{L}_{c 1}, \mathrm{~L}_{c 2}\right)$ comparison for all coatings (CSEM REVETEST® Scratch Tester, dry test)

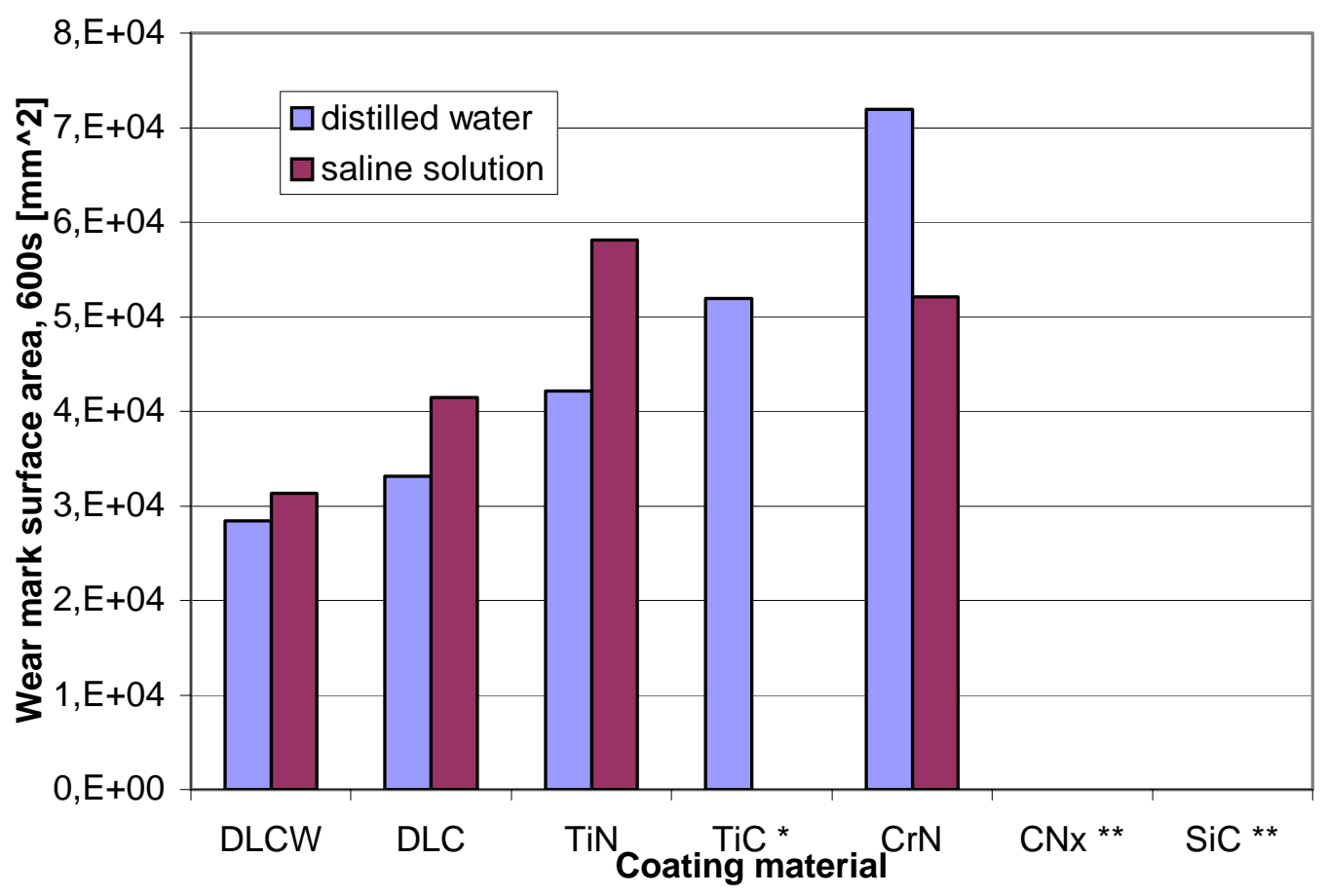

Fig. 8. Wear mark surface area after $600 \mathrm{~s}$ of testing in ball-on-flat reciprocating sliding. * coating destroyed before test end with saline lubrication; ** coating destroyed before test end with water and with saline lubrication 


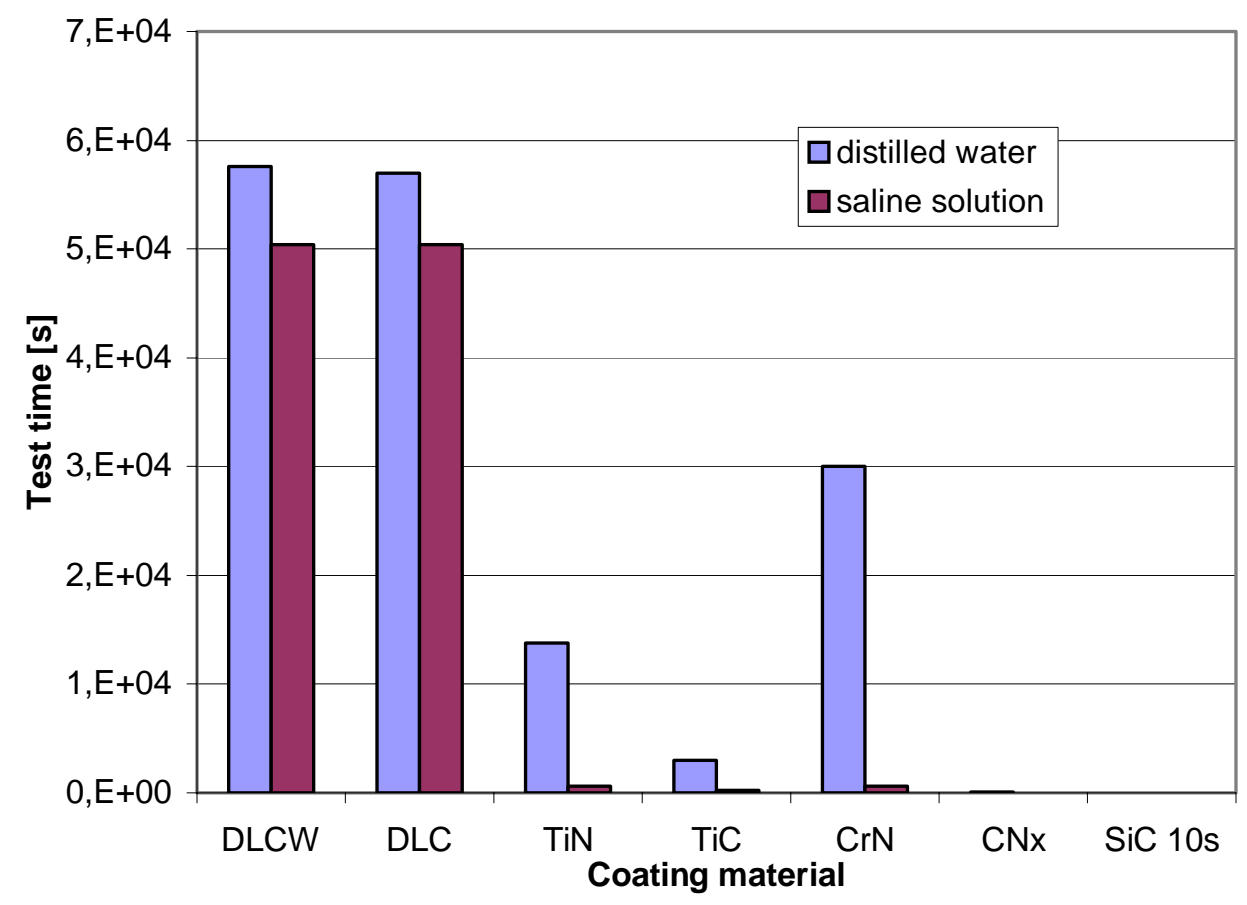

Fig. 9. Test endurance in ball-on-flat reciprocating sliding (TPZ-1 tribometer, water and saline lubrication)

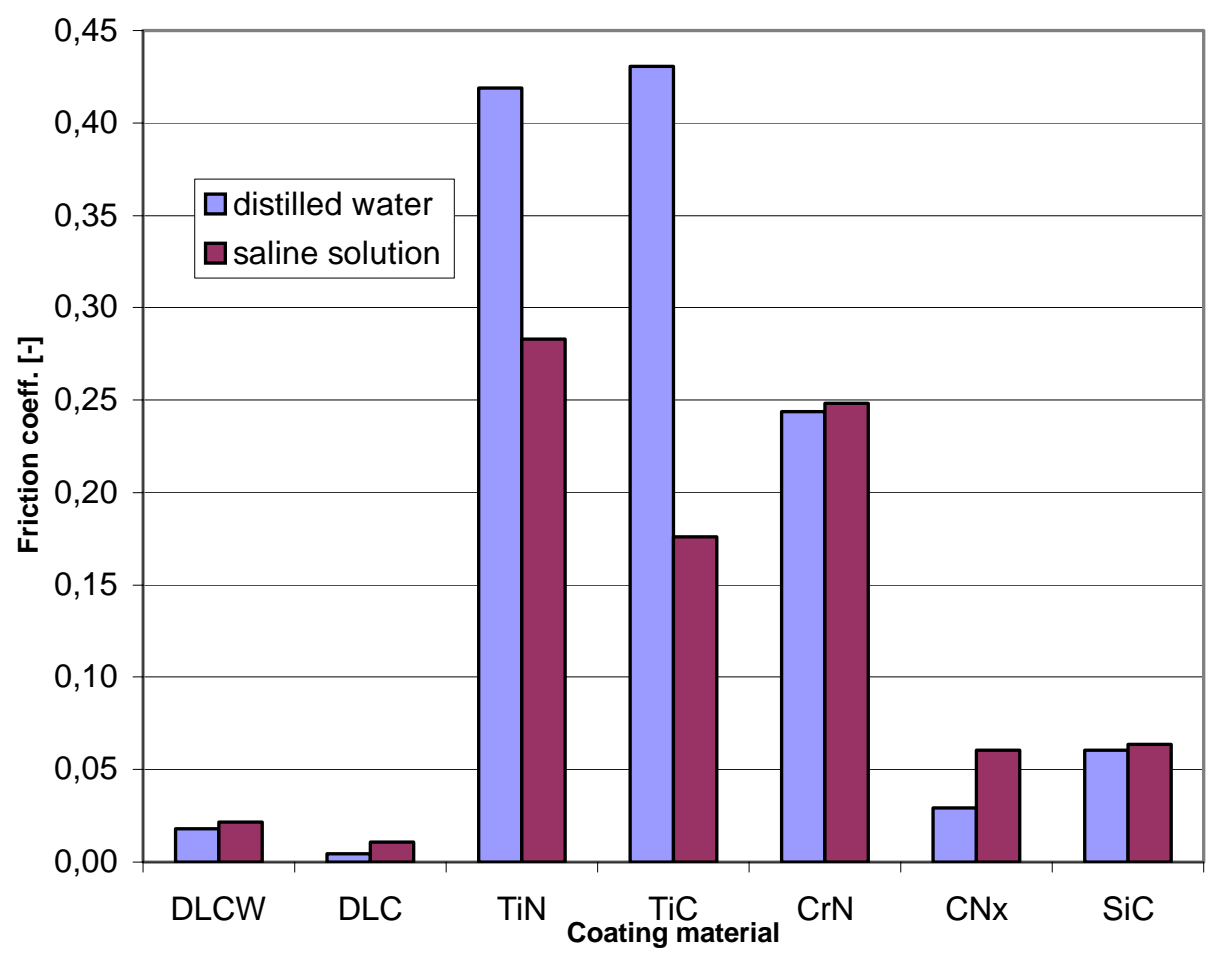

Fig. 10. Friction coefficient in flat - on - flat (ring shaped contact surf.) unidirectional sliding (PT-3 Tribometer, water and saline lubrication) 


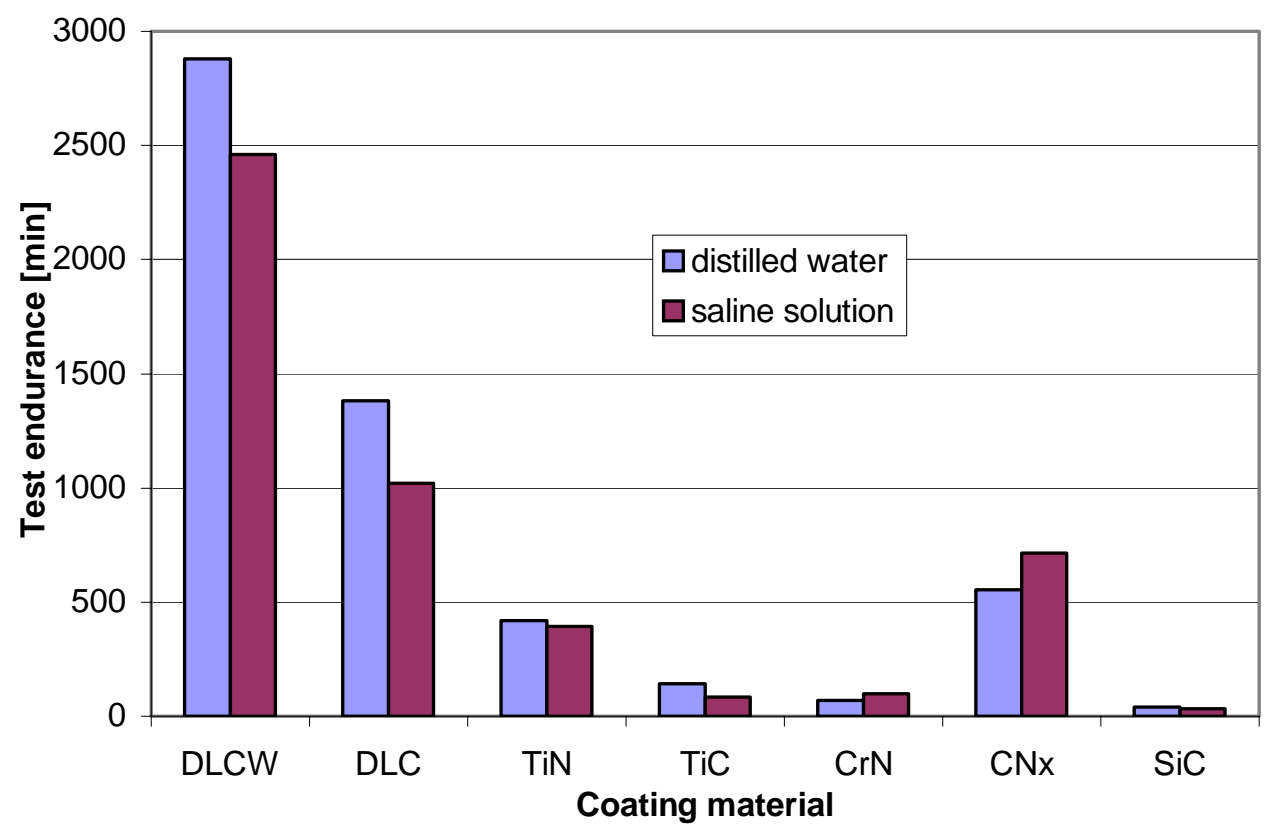

Fig. 11. Test endurance in flat - on - flat (ring shaped contact surf.) unidirectional sliding carried out in PT3 Tribometer

In each result set the coating can be indicated, which performs best (e.g. exhibits longest endurance). A ranking of test results can be created within the data set obtained from each experiment type by scoring points to each result. Best result equals 1 point, further down the ranking the number of points increases. In case of equal results equal points are scored, thus the maximum score in one set can be less than the number of coatings considered. As shown in Table 4 the experiments carried out produced a total of ten sub - sets of points awarded for each component result. The overall score is obtained by adding up the points in columns corresponding to coatings.

Table 4. Coating performance grading by points with regard to material, test type, result and lubricant

\begin{tabular}{|c|c|c|c|c|c|c|c|c|c|}
\hline \multirow[b]{2}{*}{ Test type } & \multirow[b]{2}{*}{ Lubrication } & \multirow[b]{2}{*}{ Result type } & \multicolumn{7}{|c|}{ Coating material } \\
\hline & & & DLC-W & DLC & TiN & $\mathrm{CrN}$ & $\mathrm{CNx}$ & $\mathrm{TiC}$ & $\mathrm{SiC}$ \\
\hline \multirow{2}{*}{$\begin{array}{c}\text { Scratch } \\
\text { test }\end{array}$} & \multirow{2}{*}{ dry } & Lc1 & 3 & 4 & 1 & 2 & 4 & 4 & 4 \\
\hline & & LC2 & 3 & 4 & 1 & 2 & 4 & 4 & 4 \\
\hline \multirow{4}{*}{ TPZ-1 } & \multirow{2}{*}{$\mathrm{H}_{2} \mathrm{O}$} & endurance & 1 & 2 & 4 & 3 & 6 & 5 & 7 \\
\hline & & wear rate & 1 & 2 & 3 & 5 & 6 & 4 & 6 \\
\hline & \multirow{2}{*}{$\mathrm{H}_{2} \mathrm{O}+\mathrm{NaCl}$} & endurance & 1 & 1 & 2 & 2 & 4 & 3 & 5 \\
\hline & & wear rate & 1 & 2 & 4 & 3 & 5 & 5 & 5 \\
\hline \multirow{4}{*}{ PT-3 } & \multirow{2}{*}{$\mathrm{H}_{2} \mathrm{O}$} & endurance & 1 & 2 & 4 & 6 & 3 & 5 & 7 \\
\hline & & friction coeff. & 2 & 1 & 6 & 5 & 3 & 7 & 4 \\
\hline & \multirow{2}{*}{$\mathrm{H}_{2} \mathrm{O}+\mathrm{NaCl}$} & endurance & 1 & 2 & 4 & 5 & 3 & 6 & 7 \\
\hline & & friction coeff. & 2 & 1 & 7 & 6 & 3 & 5 & 4 \\
\hline \multirow{3}{*}{\multicolumn{2}{|c|}{ Score }} & overall: & 16 & 21 & 36 & 39 & 41 & 48 & 53 \\
\hline & & distilled water: & 11 & 15 & 19 & 23 & 26 & 29 & 32 \\
\hline & & saline solution & 11 & 14 & 19 & 20 & 23 & 27 & 29 \\
\hline
\end{tabular}

Such a synthetic data set can be easily manipulated in various ways and provides a simple insight into the relative performance of each material in the tested set. In The bar graph in Figure 12 shows overall scores for all coatings as a total sum of points and sub - scores obtained for either scratch test and distilled water lubricated tests or scratch test 
and saline solution lubricated tests. Further tests are continued in order to accumulate data and experience necessary to improve the method and develop it into an easy to use result interpretation tool. For example application of corrective factors to sub sets of points can be used to correct the sensitivity of the method if such need occurs

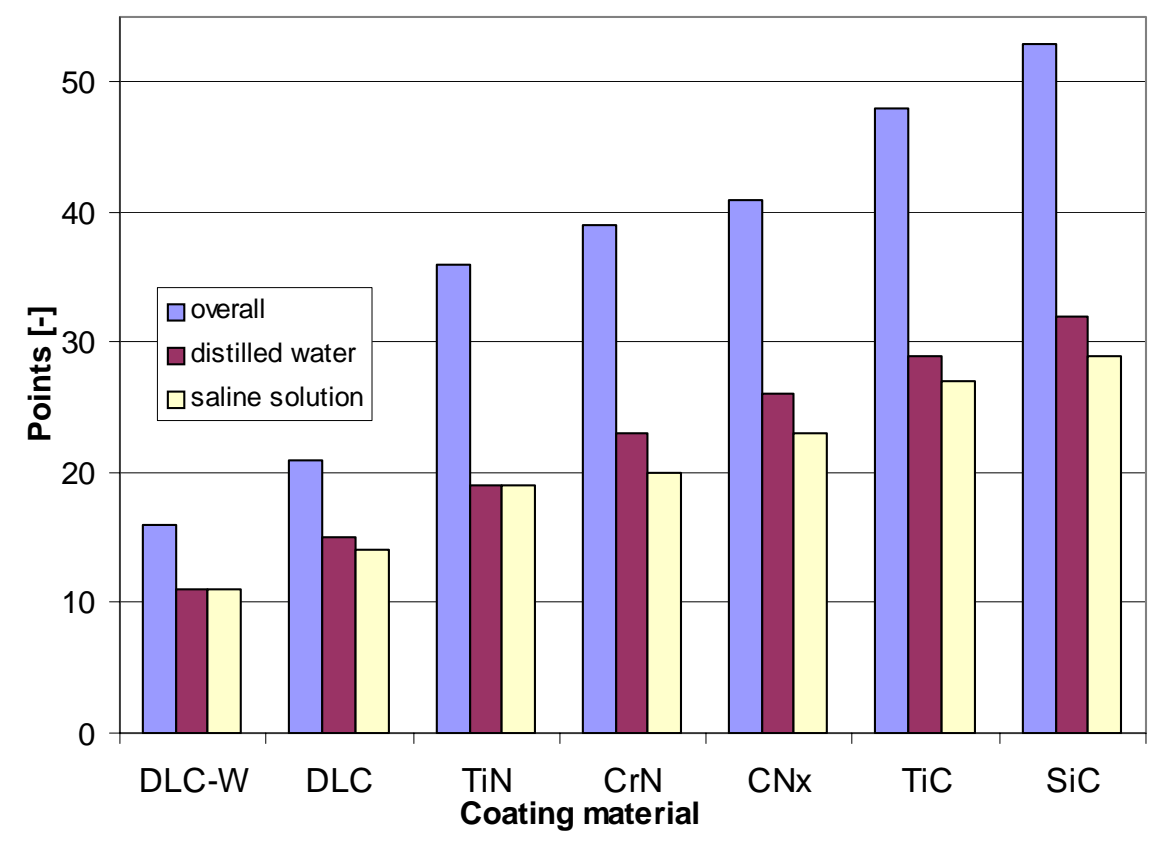

Fig. 12. Accumulated point grade score for four different tribological tests, seven coatings and two lubricants

\section{CONCLUSIONS}

The paper presents an insight into the problems of the development metal - ceramics systems for bio - medical applications, resistant to tribological wear.

Results obtained indicate, that alongside use of data obtained in various tribological tests can improve the process of coating selection for tribological applications in medical engineering; also the method can be beneficial to a wide range of material selection problems in technology.

The use of existing tribometers and test methods using different contact types and motion patterns allows to take into account different operating conditions while performing the screening of different materials. Simplicity of the tests used provides for a low cost of the procedure and can contribute to better selection of materials for testing in semi - real or real life conditions [5, 6], which require large and complex specimens and testers or experiments in living organisms; In both cases such tests are costly and time consuming.

Further work is currently under way to form fully developed tool for the selection of the set of tests, which would be best suited for the evaluation of a given target application.

\section{ACKNOWLEDGEMENTS}

The financial support from the Polish Ministry for Higher Education and Informatics in the form of research grant No N N 504411437 is hereby gratefully acknowledged. 


\section{REFERENCES}

1. S. R. Hummel, B. Partlow, Comparison of threshold galling results from two testing methods, Tribology International Vol. 37, pp. 291-295 (2004).

2. H. Czichos, S. Becker, J. Lexow, Multilaboratory tribotesting: Results from the VAMAS Programme on wear test methods, Wear Vol. 114, 109-123 (1987).

3. W. Pompe, H. Worch, M. Epple, W. Friess, M. Gelinsky, P. Greil, U. Hempele, D. Scharnweber, K. Schulte, Functionally graded materials for biomedical applications, Materials Science and Engineering A362, pp. 40-60 (2003).

4. Z.M. Jin, M. Stone, E. Ingham, J. Fisher, Current Orthopaedics (2006) 20, minisymposium: biomechanics for the frcs orth exam, pp. 32-40.

5. S. Affatato, M. Spinelli, M. Zavalloni, C. Mazzega-Fabbro, M. Viceconti, Tribology and total hip joint replacement: Current concepts in mechanical simulation, Medical Engineering \& Physics Vol. 30, 1305-1317 (2008).

6. D. Dowson, A comparative study of the performance of metallic and ceramic femoral head components in total replacement of hip joints, Wear Vol. 190, pp. 171 - 183 (1995).

7. V. Gorokhovsky, B. Heckerman, P. Watson, N. Bekesch, The effect of multilayer filtered arc coatings on mechanical properties, corrosion resistance and performance of periodontal dental instruments, Surface \& Coatings Technology Vol. 200, pp. 5614 - 5630 (2006).

8. B. Shi, O.O. Ajayi, G. Fenske, A. Erdemir, H. Liang, Tribological performance of some alternative bearing materials for artificial joints, Wear Vol. 255, pp. 10151021 (2003).

9. C. Richard, C. Kowandy, J. Landoulsi, M. Geetha, H. Ramasawmy, Corrosion and wear behavior of thermally sprayed nano ceramic coatings on commercially pure Titanium and Ti-13Nb-13Zr substrates, Int. Journal of Refractory Metals \& Hard Materials Vol. 28, pp. 115-123, (2010)

10. W. Österle, D. Klaffke, M. Griepentrog, U. Gross, I. Kranz, Ch. Knabe, Potential of wear resistant coatings on Ti-6Al-4V for artificial hip joint bearing surfaces, Wear Vol. 264, pp. 505-517 (2008).

11. T. Lubinski, Testing of friction dynamics on a tribometer PT-3/96, Proc. 1st World Tribology Congress, London, 1997.

12. Wang X.-X., Yan W., Hayakawa S. i in.: Apatite deposition on thermally and anodically oxidized titanium surfaces in a simulated body fluid, Biomaterials 24 (2003) 4631-4637. 